biopsy specimens, examined with the electron microscope, have indeed revealed the presence of viral formations of $800-1600 \AA$, resembling myxovirus-coronavirus structures (Fig.). It may help to recall that coronaviruses were only recently recognized as an independent viral unit distinct from myxoviruses in the light of serological findings. ${ }^{4}$

Our own observations, and the contributions of Drs. Spencer and Andersen, suggest that the myxovirus-coronavirus organisms that we have detected may be involved in the genesis of hepatitis, with azathioprine acting as an activator and revealer of viruses already present in the liver. Further evidence in favour of a relationship between myxoviruscoronavirus organisms and hepatitis is provided by Dr. A. J. Zuckerman and others (31 January, p. 262), who found a coronavirus in the serum of a chronic hepatitis patient, and by Holmes et al.,5 who found one in the serum of two acute hepatitis patients reacting positively for Australia antigen.I am, etc.,

\section{Gaslini Institute}

REFERENCES 1 Cachin, M., Presse Médicale, 1968, 76, 619. and Krawczynski, K., Lancet,' 1970, 2, 494.

4 Sirtori, C., Gaslini, 1970, 2, 5.

Holmes, A. W., Deinhardt, F., Harris W., Ball,, F.,
and Cine, G., foumal of Clinical Investigation, and Cine, $G$.

\section{Coal Workers' Pneumoconiosis}

SIR,-In their recent study of coal miners (29 August, p. 481) Dr. R. Ryder and his colleagues observed that impairment of ventilation did not correlate with radiological category "until the development of progressive massive fibrosis category B," but they did not comment upon the severe impairment of ventilation among miners whose radiographs they classified as normal (category O). The mean value for F.E.V.1 in category $O$ was similar to the mean value in category $B$ but lower than in the intermediate categories 1, 2, 3, and A (their Fig. 2). Moreover, F.E.V.1 values of less than 1.41 . were recorded in half the miners with category $\mathrm{O}$ and $\mathrm{B}$ radiographs but in only about one third of the miners in each of the intermediate categories (Table VI). These differences may or may not be significant statistically, but they are in keeping with an observation which has repeatedly been made in earlier studies: that miners with the radiological changes of simple pneumoconiosis tend to have a better ventilatory capacity than those with normal radiographs. ${ }^{1-5}$

It has been suggested that disability in the presence of an apparently normal radiograph might be due to focal emphysema masking the shadows cast by coal dust. ${ }^{56}$ This theory is supported by $\mathrm{Dr}$. Ryder and his colleagues' discovery that emphysema at necropsy is more often associated with punctiform opacities in the radiograph than with coarser nodulation. They point out that punctiform opacities are less striking than the nodular ones and that this contrast may be emphasized by emphysema in the surrounding lung.

Dr. Ryder and his colleagues have also demonstrated that emphysema is much more common among miners than non- miners, and that it is clearly related to impairment of F.E.V.1 during life but not to radiological category. Unfortunately, they do not indicate the emphysema count for the individual radiological categories but it would presumably be high in miners with normal radiographs (category $\mathrm{O}$ ) since their mean F.E.V.1 is lower than in most of the other categories.

It would seem, therefore, no longer justifiable to base compensation upon radiological category and to exclude from consideration disabled miners with apparently normal radiographs. These men should surely be referred for more comprehensive physiological studies and, when these reveal a pattern of dysfunction distinct from that found in non-industrial lung disease, ${ }^{5}$ disability could reasonably be attributed to their occupation.-I am, etc.,

\section{Colin OgILvie.}

\section{Royal Infirmary,}

$$
\text { Liverpool. }
$$

Research Council, Special Report Series, No Research Council, Special Report Series, No. and Higgins, I. T. T., British fournal of .

iggins, 1.7. T., Oldham, P D., Cochrane, A. L., 2,904 .

Leathart, G. L., British fournal of Industrial Medicine, 1959, 16, 153.

Ogilvie, C., Brown, K., and Kearns, W. E., British Medical fournal, 1967, 3, 10.
Rappaport, I., British Medical łournal, 1966, 1, 1356.

SIR,-We were very interested in the paper by Dr. R. Ryder and others on emphysema in coal workers' pneumoconiosis (29 August, p. 481).

The overall prevalence of pneumoconiosis in working coalminers in Great Britain is $10.7 \% .^{1}$ The findings of Dr. Ryder and his colleagues were therefore derived from the study of a selected minority group of coalworkers.

The fundamental question raised by Fletcher, ${ }^{2}$ and referred to in the introduction of the paper by Dr. Ryder and others, is whether there is more emphysema in the mining community than in the general population. It seems doubtful whether much light is shed on this question by Dr. Ryder and his colleagues as the $90 \%$ (approximately) of miners without pneumoconiosis in the United Kingdom are so poorly represented in the material they examined. Dr. Ryder and others, as the title of their paper implies, carefully refer their findings to men with pneumoconiosis. We hope they will agree that the only way to answer the question raised by Fletcher is to compare data from samples representative of the mining population as a whole with data from samples representative of the general population as a whole.-We are, etc.,

\section{S. RAE.}

D. C. F. MUIR

$$
\text { M. JACOBSEN. }
$$

Institute of Occupational Medicine, Edinburgh.

REFERENCES

National Coal Board. Medical Service and Medical Research: Annual Report, 1968-69. Human C. M., in Form and Function in the Hunt, p. 37, Edinburgh, Livingstone, 1968.
Twin Survival in Therapeutic Abortion

SIR,-In November 1969 a patient was accepted for termination of pregnancy (paras. 2 and 3, form H.S.A.1., Abortion Act 1967). She was 28 years old, and was pregnant for the third time, having conceived while taking a purely progestational contraceptive compound. The last withdrawal bleed was on 10 September 1969.

Termination was performed by the Kerslake method of intrauterine aspiration after the administration of $0.5 \mathrm{mg}$. ergometrine intravenously and the injection of $0.5 \%$ lignocaine, $10 \mathrm{ml}$. on each side of the cervix. After aspiration, when fetal parts had been identified, blunt curettage produced little debris; and no intrauterine irregularity was felt. The postoperative course was uneventful, uterine bleeding persisted for a few hours only, and the patient was discharged in 48 hours.

She returned to the clinic in February 1970 with a uterine mass compatible with 22-weeks gestation. Ultrasonic scanning confirmed the presence of a single fetus; hysterotomy was offered but refused by the patient and antenatal care was accepted. The expected date of delivery was considered to be 17 June 1970 and at 39 weeks preeclampsia developed. This was rapidly progressive and induction of labour was attempted. On vaginal examination the cervix, well taken up, would only admit one finger and the membranes were so thick that rupture proved impossible. The indication for delivery was demanding and the patient had requested tubal ligation, and so, in preference to difficult surgical amniotomy, elective caesarean section was performed.

At caesarean section through the lower uterine segment, a live term infant weighing 6 lb. 7 ozs. $(2.9 \mathrm{~kg}$.) was delivered. The placenta was implanted in the fundus and it was removed with its membranes easily. There was then found, densely adherent to the lower segment, a portion of membrane about $5 \mathrm{~mm}$. thick occluding the internal os; this appeared to represent part of the membranes of the aborted twin. It was necessary to incise this with a knife to ensure lochial drainage. The puerperium was uneventful. The female child thrived and in the view of the paediatrician was normal for her age.

The symmetrical placental implantation on the fundus together with the smoothness of the membranes camouflaged the continuing presence in the uterus of a twin to an aborted fetus. No apparent damage had resulted from the use of ergometrine prior to aspirations, perhaps because the membranes remained intact. It seems unlikely that many such cases will eventuate because the placenta is most commonly eccentrically implanted and its edge is accessible to the curette.-I am, etc.,

\section{P. Douglas.}

Department of Obstetrics and Gynaecology, London N.1.

\section{Reasons for Abortion}

SIR,-Your leading article (15 August, p. 362) states that "According to the inquiry held recently by the Royal College of Obstetricians and Gynaecologists the great majority of consultants in that specialty con- 
sider that the real problem of the Abortion Act is not its wording but its interpretation." In my opinion, both as a gynaecologist and also as a barrister-at-law, it is the way the Abortion Act is being operated that is the crux of the matter.

Before the passing of the Abortion Act gynaecologists who conducted their practices on strictly ethical lines could seldom find good medical indications for the performance of therapeutic abortion where the life or health of the mother were endangered by pregnancy and would be improved by termination. Rarely abortion was medically justified in severe diabetes; severe class III or class IV heart disease where decompensation occurred before the fourteenth week of pregnancy; malignant hypertension and in chronic nephritis complicated by pronounced albuminuria, hypertension, and oedema. Indeed, the last indication was probably the most valid of all, although the end results were, inevitably, poor. The fact that valid medical indications for therapeutic abortion were few and the medical need for termination of pregnancy was very rare was well illustrated by Cosgrove and Carter's ${ }^{1}$ investigations at the Margaret Hague Maternity Hospital, where therapeutic abortion was performed once only in 16,750 deliveries. Applying this incidence of therapeutic abortion to Great Britain, one would expect only 48 terminations of pregnancy annually in 800,000 births.

What concerns me, therefore, is to read that there were 22,256 therapeutic abortions in the last eight months of 1968, (5 July 1969 , p. 62), of which 18,000 were performed for psychiatric reasons. Dr. R. E Hemphill, who wrote the chapter on mental disturbances in pregnancy and the puerperium in my Textbook of Gynaecology and Obstetrics, ${ }^{2}$ had the following to say about termination of pregnancy.

"Termination, although often requested, can rarely be justified on psychiatric grounds. In order to comply with the law, it must be shown that pregnancy constitutes a serious risk to the mother's life, mental or physical health, which cannot be treated or prevented in any other way. . Termination occasionally has to be recommended in unstable women of poor personality and limited intelligence whose disturbed behaviour and threats of suicide seem genuine but who lack the understanding to cooperate in treatment. They are usually married wome with several children, indifferently cared for The psychiatrist will have to decide whether $h$ knows of any form of treatment that will restor the patient to health and prevent suicide and which can be carried out, assuming that the patient is not so seriously ill that compulsive detention in a psychiatric hospital can be legally enforced. If the answer is no, he will have to recommend termination." 3

Quite apart from the guilt reactions analvsed bv Ekblad ${ }^{4}$ and by Polonio and Figueirado, ${ }^{5}$ who found that at least $25 \%$ of women who submitted to legal abortion in Scandinavia bitterly regretted having done so subsequently, there is, I understand, evidence to suggest that women who undergo termination of pregnancy for psvchiatric reasons where other treatment would be preferable may be left in a worse state than they were before. I well remember how the late Dr. Henry Wilson, consultant psychiatrist to the London Hospital, used to reach a decision in cases of pregnancy complicated by psychiatric disturbance. He would carefully explain to the patient that termination of pregnancy was merely one aspect of treatment and that after it had been performed they would have to be admitted to a psychiatric hospital for further treatment. Those really requiring therapeutic abortion eagerly agreed to go into hospital but the vast majority who were "shamming" indignantly refused even to consider doing so. Thus were the sheep readily divided from the goats.

I am, of course, fully aware of the fact that there are differences of opinion among psychiatrists on the subject of therapeutic abortion, but I don't think that I would be grossly mistaken if $I$ were to say that many would agree with Dr. Hemphill's views. Furthermore, there would be few, I think, who would be willing to swear on soul and conscience that psychiatric disturbances were commonly a valid medical indication for termination of pregnancy.

In conclusion, therefore, one of my main concerns about the Abortion Act is that it is giving cover to vast numbers of therapeutic abortions performed theoretically for the amelioration of psychiatric dangers to the mother's life or health which really do not exist and which would never stand up in a court of law if they were to be challenged.I am, etc.,

$$
\text { D. G. Wilson Clyne. }
$$

St. Austell, Cornwall.

\section{ReFERENCES}

Cosgrove, S. A., and Carter, P. A., American
fournal of Obstetrics and Gynaecology, 1944,

Clyne, D. G. W., A Textbook of Gynaecology and Obstetrics. London, Lonemans, 1963

and Obstetrics, by $A$ Tertbook of Gynaecology and Oonstetrics, by 1963 .

Ekblad, M.: Acta Psychiatrica et Neurologica Scandinavica, 1955. Suppl. No 99 .

für Psychiatrie und Neurologie, 1955, 130, 304.

\section{Superfluous Medication}

SIR,-As a contribution to the spirit and purpose of this "conservation year" could we not do something about the superfluous medication which litters the viscera of our patients?

Concern is sometimes expressed about the abuse by the public of aspirin and amphetamines, not to mention more dangerous drugs. Can it be said that we as a profession have done all we should in the way of educating our patients to avoid unnecessary medication?

The complexities of this problem will not be fully appreciated by those who are unfamiliar with the mystique of general practice. Of this the most pertinent point is that the prescription represents the consummation of a ritual; the more speedily the practitioner presses to this climax the sooner his surgery is finished. It is a very instructive and at the same time exhausting exercise to try to handle heavy surgeries without recourse to expediency in prescribing. Incredulity. indignation, and virtual sit-down strikes have to be faced if it is suggested, for example, that a patient with influenza requires no medication. The practitioner will be bitterly criticized if any unforeseen complication should ensue. On the other hand complaints about reckless prescribing are almost unknown.

The consultants' record is little better. Routine recommendation of an indefinite regimen of tranquillizers after a negative investigation is just as frequent today as was the routine recommendation of barbiturates 20 years ago.

The prescription explosion has created a climate of opinion which virtually forces a doctor to prescribe a week's course of analgesics and an elegantly packaged rubefacient for a trifling bump, and he is branded as callous and unfeeling if he fails to press multicoloured tranquillizers on every girl who is jilted and every difficult elderly lady.

Have we the right to be indignant when youngsters indulge illicitly in tablets which we have been prescribing "ethically" by the million?

It is a very time-consuming, exacting, and thankless task for a general practitioner to struggle against the current trend of maximal medication. If the B.M.A. or Royal College of Physicians would make an appropriate public statement it would rapidly deflate the tablet craze, reduce the pressure on our surgeries, the incidence of iatrogenic disease, and the prodigeous stocks of tablets accumulating in kitchen cupboards.-I am etc.,

Sheffield.

C. H. FogGITT.

\section{Sensitivity Tests in Tuberculosis}

SIR,-Your leading article on the above subject (5 September, p. 538) would have been more complete if some reference had been made to the scheme which operates in Scotland. In Scotland all sensitivity tests are conducted in one central laboratory, the various isolating laboratories having agreed to centralize all the testing in this one laboratory. Nothing is done to prevent any local bacteriologist carrving out his own tests, but at the same time he is expected to send a representative culture to the Reference Laboratory where the "official" results are recorded, reoorted back to the bacteriologist sending in the culture. and an annual return made to the Home and Health Department in Edinburgh.

As a matter of interest, very seldom does the Reference Laboratory record a different reading from that of anv of the isolating laboratories that carry out their own tests. It does on occasion happen that there is variation but not often. Of course, it could be that the general standard of bacteriology is higher in Scotland than in the areas reported uoon by Marks. ${ }^{1}$ but then we in Scotland have been spared up until now that Jack-of-all-trades-the clinical pathologist-and bacteriology is usually carried out here by professional bacteriologists. -

I am, etc.,

LAWRENCE G. BRUCE, Director. Scottich Mycobacteria Mearnskirk Hospital,

Renfrew.

REFERENCE Marks, T., Monthly Bulletin of the Ministry of
Health

\section{Ban on Amphetamines}

SIR.-Some doctors find difficulty in accepting a total ban on the prescription of amphetamine preparations because they treat one of those rare patients for whom an amohetamine is. in their opinion, essential The effect of the ban can still be achieved by prescribing these amphetamine preparations in the number contained in the manu- 